\title{
¿Qué hay de popular en un diario como La Cuarta?
}

\section{In What Sense is La Cuarta a "Popular" Newspaper?}

\section{Eduardo Santa Cruz A.}

Universidad de Chile

eduardosantacruza@gmail.com

\begin{abstract}
Resumen
El artículo pretende problematizar la noción de "popular" que caracteriza el discurso del diario chileno La Cuarta. Con este objetivo revisa algunas de las maneras en que se manifiesta históricamente el sentido de lo popular en el país y luego analiza cómo estos sentidos son recontextualizados por el periódico al interior de una sociedad mediatizada, masificada y postdictatorial.
\end{abstract}

Palabras clave: Cultura popular, Chile, prensa, La Cuarta.

\begin{abstract}
The paper seeks to problematize concept of "Popular" that characterizes the discourse of Chilean newspaper La Cuarta. With this purpose, it reviews some of the ways the popular manifests historically in Chile and then analyzes how these historical senses are recontextualized by the newspaper La Cuarta within a mediated, massive and post-dictatorship society.
\end{abstract}

Keywords: Popular Culture, Chile, the press, the Fourth.

\section{Introducción}

La industria cultural chilena durante el siglo XX generó diversos productos culturales, en variados formatos y géneros con la pretensión de erigirse en representaciones de lo popular, así como de autodenominarse servidores y defensores de sus intereses. Se trata de una prensa dirigida hacia lo popular y proveniente de otros sectores con definidas motivaciones económicas y/o ideológicas. Así, por ejemplo, la prensa escrita ha constituido uno de los espacios comunicacionales donde dicha tendencia se mantiene desde fines del siglo XIX, es decir desde los momentos en que, al calor del proceso de modernización liberal-oligárquico se comienzan a establecer las bases de una cultura y un 
mercado cultural de masas, en conjunto con el desarrollo en su interior de lo que, en otro lugar, hemos llamado esfera pública plebeya (Ossandón y Santa Cruz, 2001). Es una prensa polémica y controvertida que algunos llamarán "sensacionalista" o "amarilla", buscando entenderla como simple reflejo mimético de fenómenos externos, específicamente de la prensa norteamericana.

Este tipo de prensa tuvo su máxima expresión en un diario, Clarín, que llegó por lo menos a disputar la primera circulación nacional (Santa Cruz, 1988). Clarín, que apareció el 21 de septiembre de 1954, parece ser la expresión más completa de este tipo de prensa que Sunkel denomina prensa popular de masas. Sin embargo, existen antecedentes de prensa dirigida a y sobre lo popular desde fines del siglo XIX. Es el caso de El Chileno (1882-1924), conocido como el diario de las cocineras y luego, El Diario Popular (1902-1906), ambos de tendencia católica-conservadora (Santa Cruz, 2000). Más tarde, aparece el diario Los Tiempos, que se editó entre 1922 y 1931; es el primero en introducir el formato tabloide, con el uso de colores y fotografías en primera plana, así como grandes titulares. Sus contenidos versaban fundamentalmente sobre noticias deportivas, de espectáculos y cine, crónica policial, caricaturas, etc. Según señala Sunkel, "...Es el diario que inicia el reportaje policial en gran escala, el primero que le da gran importancia al suceso delictuoso del día"(Sunkel, 1986). Luego de algunos años, apareció Las Noticias Gráficas, que se publicó entre 1944 y 1954, que puso aún más énfasis en la crónica policial y de escándalo y denuncia. También se destacó por la incorporación de refranes y giros del habla popular.

El mismo año que desaparece este último es fundado Clarín. Sunkel recalca que se trata de una empresa periodística y, en cuanto tal, que su criterio determinante de funcionamiento y gestión es la búsqueda de beneficios. Sin embargo, advierte que la particularidad del diario estriba en que dicho criterio central está mediatizado por opciones político-culturales que le confieren una especial identidad. Asimismo, cabe señalar que este tipo de prensa no es en ningún caso exclusivo de nuestro país, sino que se manifiesta en otros países de la región. Un caso emblemático es el del argentino Crítica (Saitta, 1998).

\section{La Cuarta y la continuidad de un modelo de prensa}

Durante la Dictadura y a pesar de la condenación lapidaria que se quiso imponerle a este tipo de prensa, el Consorcio Periodístico de Chile, propietario de La Tercera, terminó por fundar La Cuarta, cuya primera edición apareció el 13 de Noviembre de 1984 y que recogió numerosos elementos de la experiencia de Clarín. Para ello, recurrió a un conjunto de elementos propiamente periodísticos, que incluso la llevaron durante muchos años a copiar la portada, colores, diagramación, secciones, selección de contenidos, lenguaje, etc. La diferencia sustancial es que en La Cuarta la dimensión predominante de su estrategia es la comercial, la 
cual no sólo subordina lo cultural, sino que elude lo específicamente político o asume allí una distancia que diluye su fuerza discursiva. Su relación con el pueblo, es más bien de servicio a los necesitados, de auxilio y beneficencia, previamente lavadas de cualquier contaminación política (Alvarado, 1997; Sunkel, 2002).

Sin embargo, en la visión de Sunkel, el diario se inscribe plenamente en la matriz simbólico-dramática que, como vimos, dicho autor instala como mecanismo discursivo de base de este tipo de prensa. Dicha matriz incorporaría dos elementos centrales: por un lado, la utilización de un cierto tipo de lenguaje que deviene de una concepción religiosa del mundo, es decir dicotómica (bien/mal; perdón/castigo) como mecanismo básico de representación de la realidad. En este punto se manifiesta la diferencia fundamental con Clarín que señalábamos en el párrafo anterior; mientras éste leía la vida social y política traduciendo esas categorías polares a la vida humana y sus relaciones en un contexto histórico específico (ricos/pobres; avaros/solidarios), La Cuarta se limita a traducirlas en términos de individuos enfrentados a la dureza de la vida.

De igual forma, predomina una cierta estética, según Sunkel basada en el contraste objeto/sentimientos y su figuración por medio del color, lo que tendría una ligazón históricocultural con la imaginería religiosa barroca colonial. Esta dramatización apelaría a sentimientos, tales como el miedo, el dolor, la alegría, el sufrimiento, etc. para generar sensaciones e impresiones más que para suscitar una reflexión o alimentar un juicio racional.

La matriz cultural aludida sería recogida a lo largo del siglo XX por la industria cultural en una diversa gama de productos y narrativamente vehiculada a través del melodrama como formato básico en la música, la literatura, el cine y la TV (Martín Barbero y Muñoz, 1992). Esta visión apunta a poner de relieve ciertas disposiciones y competencias culturales que serían propias de la cultura popular latinoamericana. Como señala Martín Barbero, alude a

...la competencia cultural de los diversos grupos que atraviesa las clases, por la vía de la educación formal en sus distintas modalidades, pero sobre todo las que configuran las etnias, las culturas regionales, los "dialectos" locales y los distintos mestizajes urbanos en base a aquellos. Competencia que vive de la memoria - narrativa, gestual, auditiva- y también de los imaginarios actuales" (Martín Barbero, 1987).

Desde allí, dicho autor elabora su teoría de las mediaciones, entendiendo a éstas como el lugar desde donde es posible percibir y comprender las relaciones y mutuas determinaciones entre el espacio de la producción y la recepción. De este modo, los medios y la industria cultural funcionan asumiendo, y con ello legitimando, las demandas que vienen desde los grupos receptores, pero, a su vez, dicha legitimación solamente se produce en tanto lo popular es resignificado en la perspectiva del discurso hegemónico.

Si bien esta mirada pone el acento en las relaciones más que en las autosuficiencias y en la historicidad más que en esencias permanentes, de todas formas supone algún nivel mínimo 
de homogeneidad cultural en el mundo popular, necesario para constituir un espacio social y cultural distinto del oficial y hegemónico, cuando no alternativo y contestatario o al menos disruptivo.

La prensa populista en nuestro país reconoció esta potencialidad del actor social popular y por ello, cada uno de sus exponentes elaboró una noción identitaria de aquel que pretendía servir, como referente de sus lectores. Los diferentes contextos históricos, así como los específicos intereses económicos y/o ideológicos de sus propietarios determinarían las diferencias en la idea de pueblo que dichos medios sustentaron. $\mathrm{La}$ Cuarta no ha sido ajena a esto. Como veremos, durante casi 20 años, desde su fundación hasta el año 2003, el diario mantuvo un perfil y una estrategia periodística que lo colocaba en una línea de continuidad con los diarios anteriores. En los párrafos siguientes daremos cuenta de estas características, para así poder resaltar mejor el cambio producido en los últimos tres años.

En primer término, cabe destacar la especificidad de esta prensa y de $\mathrm{La}$ Cuarta, en orden a demarcarse de la llamada prensa amarilla o sensacionalista, desarrollada en EE.UU. y algunos países europeos. Isabel Awad y Guillermo Soto dejan claro estas distinciones, al enfatizar que "...la popularidad de La Cuarta no tendría tanto que ver con el sensacionalismo tal y como éste se da en periódicos estadounidenses y europeos, sino con el empleo de un lenguaje profundamente arraigado en la cultura popular" (Awad y Soto, 202: p.62). La existencia de una matriz cultural emergida de las condiciones históricas específicas latinoamericanas, sería el fundamento de la diferencia. Esta distinción es análoga a la que Martin Barbero realiza para separar a la telenovela latinoamericana de la llamada soap opera, o serial televisiva estadounidense (Martín Barbero y Muñoz, 1992).

El lenguaje usado por el diario aparece así como un factor clave y central. Según Awad y Soto, el periódico no intenta reproducir o imitar en tanto caricatura la manera cotidiana del habla popular, sino que más bien incorpora al lenguaje de la prensa moderna recursos gramaticales típicos de esta habla. En esa dirección, el lenguaje y, agregamos, la narrativa utilizada, constituyen el elemento vinculante entre el diario y su público popular:

...En un periódico que se autodenomina "amigo" y que "pretende identificarse con quienes siempre han estado como dejados de la mano de Dios", la información es sólo una parte. Tan importante como ella, resulta el vínculo que se construye entre el medio y sus lectores (Awad y Soto, 2002: p.61).

Por ello, agregan, aportando una intuición que desplaza la tradicional lectura ilustrada acerca de la supuesta vulgaridad y simpleza de este tipo de diarios, que

...Precisamente el énfasis en el vínculo que manifiesta La Cuarta sugiere que la retórica de la oralidad no corresponde a la búsqueda de un lenguaje deficitario más accesible para quienes carecen de un ordenado manejo de la lengua escrita, independientemente de que la creación 
de un clima afectivo también favorece la entrega de contenidos. En vez de ello, el lenguaje de La Cuarta construye una situación de conversación con el lector, implicándolo tanto cognitiva como afectivamente (Awad y Soto, 2002: p.62).

Esto último cuestiona incluso la propia tesis de que este tipo de prensa estaría ajena a toda racionalidad o difusión de contenidos informativos, sino que éstos serían colocados en una relación comunicativa que supone

...la construcción de relaciones de cercanía con el mundo cultural de sus lectores/as. Ello significa que esta prensa no es algo externo al mundo popular, sino, por el contrario, que requiere incorporar o "capturar" algunos de sus elementos culturales básicos ya que, de otra manera, ella simplemente no tendría sentido para sus lectores/as (Sunkel, 2002: 124).

En este sentido, agrega Sunkel, se establecen tres niveles de cercanía y relación entre el diario y su público. En primer lugar, conectándose con la oralidad del mundo popular; luego, conectándose con ciertas experiencias vitales de sus lectores y, finalmente, conectándose con un cierto modo de decir o narrar los acontecimientos, visto por los lectores de La Cuarta como realista. Con respecto a la percepción y valoración del diario por parte de sus lectores, el texto citado también señala cómo éstos manifestaban cinco aspectos que reconocían positivamente en el diario: la prescindencia de la política; el humor; el uso de un lenguaje popular; el realismo en el tratamiento de las noticias, especialmente de violencia y delincuencia y la forma de contar los acontecimientos.

Esto lleva a Sunkel a afirmar que hay en este caso un modo, también particular de enfrentarse a la información periodística,

...Si la prensa sensacionalista conecta al lector popular con su propia realidad, entonces, podemos afirmar que para estos sectores la lectura no tiene el mismo sentido que en la cultura ilustrada. No es un informarse de lo que ocurre en la actualidad nacional e internacional. Es un "informarse" de lo que nos está ocurriendo a "nosotros", o más bien, de lo que estamos viviendo (Sunkel, 2002: 129).

Por otro lado, y no menos importante, el diario recurre a otro elemento decisivo para lograr esa estrecha vinculación con el mundo popular, cual es la incorporación del humor. La ironía, la parodia, la sátira, etc. como una forma de enfrentarse ya sea al poder o a las dificultades de una existencia precaria, por parte de los sectores subalternos y/o dominados, ha sido considerada como un elemento que se remonta a través de los siglos en la cultura occidental, y en ese sentido, la cultura popular chilena no sería una excepción (Salinas, 1996). Así, esta prensa constituye, según Sunkel, un medio de masificación y difusión de temas, 
lenguajes, una cierta estética y, agregamos, de una cierta manera de estar-en-el-mundo, presentes en la cultura popular.

En otra dirección, aunque haciéndose eco de lo anterior, Roxana Alvarado pone el énfasis en la operación discursiva puesta en acción por La Cuarta, en lo que se refiere a su caracterización de lo popular y a su ubicación en el contexto nacional. Hace notar que en su primera edición publica por única vez hasta ahora una editorial. En dicho texto el diario estableció una suerte de declaración de principios que delimitaba cultural y políticamente su campo discursivo. Así, afirmaba que

...No queremos que esta tribuna se convierta en un foro político. Ni a favor ni en contra de las autoridades o de quien sea. Por desgracia siempre la política es centro de discordia y antagonismo y esos sentimientos no concuerdan con la amistad que le estamos ofreciendo (...) La Cuarta quiere ser un amigo para desahogarse y un hombro fraterno en donde llorar sus penas. Publicaremos sus cartas para que las autoridades escuchen la voz del pueblo a través de este diario que pretende ser su vocero (...) La Cuarta pretende identificarse con quienes han estado como dejados de la mano de Dios (...) el pueblo no lo conforman sólo los cesantes, los más pobres y aporreados por la vida. El pueblo lo forman los 11 millones de chilenos. El hecho que busquemos la amistad y confianza con los "de abajo" no significa que le buscaremos odio y bronca a los de arriba. Al contrario intentaremos acortar la distancia y borrar diferencias que tanto daño hacen a la patria.

El diario intenta instalarse como un vocero de los sectores populares, pero rehuyendo los aspectos políticos de esa representación; es decir, se trata de una vocería despolitizada, con lo que, recalca la autora, se niega el aporte a la constitución de un campo popular que pugne por incidir, desde su particular lugar social, en los espacios e instrumentos centrales de decisión del país. La autoexclusión del diario de "la política", vista como un lugar de discordia y desunión nacional, no le concede, entonces, a los sectores populares la posibilidad de interpelar a la sociedad con su propia visión del país, como si lo hacía Clarín, el que, por el contrario, consideraba que constituía su misión fundamental.

Como señala Alvarado, se trata de separar drásticamente lo político y lo social, el que es reducido al ámbito del drama humano, de los problemas locales y cotidianos. Agrega, que lo que el diario hace es denunciar los problemas, pero sin llevarlos a planos conflictivos, es decir, sin transformarlos en problemas políticos. Por su lado, Sunkel y en la misma dirección, afirma que el autodesignado rol de vocero de los sectores populares que proclama el diario, implica ser un medio para que las autoridades se enteren de la voz popular, pero a condición de no transformarse en una tribuna política.

Sin embargo, lo anterior le permitió al diario, especialmente durante los años '90, conectarse con los procesos de atomización y fragmentación que aceleradamente comenzó a vivir la sociedad chilena y sobre los que volveremos más adelante. La representación de lo 
popular en $\mathrm{La}$ Cuarta en esa década abarcó la creciente heterogeneización que vivieron esos sectores. Al respecto, Alvarado afirma que el diario construye un discurso que da cuenta de la gran fragmentación social, informa acerca de los trabajadores del sector público, de los establecidos en pequeñas empresas, medianas y grandes, del enorme y nuevo contingente de mano de obra flexible, de los microempresarios, de los allegados, de los cesantes, de diversas formas de marginalidad (delincuencia, criminalidad, prostitución, homosexualidad, violencia, etc.), así como del resto de los actores sociales que generalmente tienen mayor cabida en los otros medios (políticos, empresarios, la jerarquía eclesiástica, estudiantes, etc.). En este sentido, La Cuarta logra dar cuenta de una realidad social mucho más rica y auténtica que la gran mayoría de los medios de comunicación.

Luego, la autora agrega que si bien el diario no elude la denuncia de los problemas sociales, lo hace siempre desde la perspectiva del drama humano e individual, con lo que

...la representación de la gran diversidad social, sobre todo a nivel popular - donde encuentra su mayor riqueza representativa- no va acompañada de una construcción de nexos o relaciones entre cada sector (...) esencialmente porque no se ahonda en las causas, sino que se restringe a presentar el hecho en forma de denuncia más bien fenomenológica, que responde a causas muy particulares (Alvarado, 1997: 204).

En resumen, lo anterior implica que este manejo discursivo, como señalamos, tiende a separar lo político de lo social, descontaminando un ámbito del otro. Más aún, cuando los propios hechos alcanzan cierta dimensión que hace evidente un grado de generalización y, con ello, de politización, "...la estrategia de La Cuarta tiende a enfatizar el lado humano del conflicto en cuestión. Desvía la noticia hacia los aspectos dramáticos del conflicto, remeciendo la sensibilidad y los sentimientos piadosos, llegando algunas veces a criticar abiertamente la politización del problema" (Alvarado, 1997: 204). De esta forma, la denuncia social en términos de dramas humanos le permite a $\mathrm{La}$ Cuarta el juego de una representación popular comprometida, pero despolitizada.

En ese mismo sentido, Alvarado hace notar que en el uso del humor por parte del diario hay un aspecto que los otros autores no mencionan, ya que

...si bien este elemento tiene mucha relación con formas de expresión de la cultura popular, también es usado como mecanismo de posicionamiento ambiguo. El juego de la ironía permite un margen de movilidad de la opinión, pues no es un juicio claro y manifiesto, sino más bien algo que se dice pero no se dice (...) dándole un sentido múltiple y dispar al discurso (Alvarado, 1997: 205). 
En definitiva, para la autora, el posicionamiento político de La Cuarta tiende a expresarse en un discurso donde se hace manifiesta su opción por los pobres, en el contexto de un sistema que aparece algunas veces injusto, pero cuya legitimidad nunca es puesta en duda.

Lo anterior se expresó durante años en una estructura formal que no tuvo mayores variaciones y en la que, como lo analizan algunos de los autores citados, la portada jugaba un papel central, manteniéndose inalterable el titular principal con letras rojas sobre un hecho policial, preferentemente de carácter pasional, y la fotografia de una mujer semidesnuda distinta cada día. Sobre esto último cabe hacer una reflexión. Los contenidos de tipo sexual, más o menos explícitos, a nivel de la palabra y la imagen, han sido característicos de este tipo de diarios. Sin embargo, la fotografia de portada no era, como las del poster llamado Bomba 4, que aparece los viernes, provenientes de publicaciones o agencias internacionales, sino que era tomada durante el verano en los balnearios más distinguidos y conspicuos del país. Es decir, la mujer cuya imagen se difundía a lo largo de todo el territorio, era una chilena más, pero generalmente perteneciente, a juzgar por su aspecto, a sectores sociales más bien acomodados. Considerando el público lector, preferentemente masculino y de sectores populares, no es aventurado señalar el simbolismo que contenía, en orden a entregar al lector la imagen de un tipo femenino que en la vida real no solamente resulta inalcanzable, sino con el que sólo se podía mantener una relación de subordinación.

El interior del diario, por su parte, mantenía en términos de espacio la importancia concedida a la crónica policial y otros ámbitos de la vida nacional, junto a las secciones dedicadas al deporte y el espectáculo. Con respecto a esta última sección, si bien ocupaba un espacio importante que aumentaba los días viernes, configuraba un espacio delimitado y específico que no contaminaba otras secciones, es decir, respondía a la estructuración clásica del periódico liberal moderno que fragmentó la realidad en compartimentos presentados como secciones específicas. Por otro lado, en el ámbito del espectáculo el diario presenta otra particularidad. Era el único periódico que recogía y le daba cabida a lo que siempre ha sido una especie de lado oscuro, cual es el mundo del cabaret y de las vedettes. En ese sentido, la mujer que trabaja como striptisera era tratada en tanto que artista y colocada a la par que aquellas otras cantantes, actrices o animadoras respetables (Monroy y Bahamondes, 2001).

Finalmente, durante esta etapa que duró hasta hace algunos años, según la investigación que expone Sunkel, el diario se dirigió preferentemente a un público

...constituido mayoritariamente por personas de estrato bajo y medio bajo y con escaso capital educacional. Existe una proporción relativamente mayor de lectores hombres (...) y el público del diario aumenta proporcionalmente con la edad. Además, este diario llega a personas que trabajan en empleos informales (trabajadores por cuenta propia, comerciantes ambulantes, etc.) o en condiciones de precariedad (conductores de locomoción colectiva, conserjes de edificios, etc.) (Sunkel, 2002: 69). 


\section{Pueblo y multitud en el discurso de La Cuarta}

En Mayo del 2003 se produce una importante transformación del diario La Cuarta: "...el escaparate donde se exhibía la muerte y la sangre era ahora ocupado por la vida íntima de los famosos y sus pequeños grandes dramas" (Fuentes y Otazo, 2005: 3). De esta forma el medio asumía y se integraba a un cambio significativo que se estaba operando en el medio periodístico nacional y en el que su competidor directo, Las Ultimas Noticias, ya se había embarcado y con éxito.

Como manifestación de procesos profundos de cambios sociales y culturales, generados por el desarrollo de las tendencias hegemónicas de la actual fase de la modernización capitalista, se había venido configurando e hizo eclosión en esta década una suerte de nuevo espacio público, construido desde una convocatoria mediática y que, paulatinamente, se ha ido consolidando como aquel que concita uno de los más altos grados de interés de parte de los públicos consumidores de información y entretención.

Se trata de aquello conocido corrientemente como la farándula. Una suerte de star system (Morín,1964) criollo constituido por animadores televisivos, actores y actrices, ciertos intelectuales, deportistas, periodistas y al que no son ajenos empresarios, políticos, militares y sacerdotes. Se construyen allí figuras públicas, presentadas muchas veces como arquetipos sociales y referentes identitarios. Son los famosos, líderes de opinión buscados ansiosamente para campañas publicitarias, políticas o de servicio público. Incluso ha emergido la curiosa figura del opinólogo, sujeto capaz de comentar y opinar sobre cualquier tema, legitimado justamente por ser ignorante de aquello sobre lo que emite sus juicios y por enfrentar los distintos temas desde el sentido común más ramplón.

No se trata de afirmar que el mundo del espectáculo, en general, no haya generado antes en Chile la aparición de figuras públicas reconocidas socialmente, es decir, famosas. Por el contrario, desde los orígenes mismos de la industria cultural y la cultura de masas desde fines del siglo XIX esto ha existido porque es un fenómeno que les es consustancial (Ossandón y Santa Cruz, 2005). Sin embargo, en la mayor parte del siglo XX ello se desarrolló en lo que Verón denomina sociedad mediática, es decir, aquella donde los medios se instalan, es decir, ocupan un cierto lugar junto a otras instituciones o actores sociales. Lo importante es que todos ellos conservan un lugar y una dinámica relativamente autónomas, lo cual implica que los medios operan en el plano de la re-presentación (más o menos deformada) de la sociedad. Ello implica también el desarrollo de ciertas formas comunicacionales que se expresan en el uso de ciertos géneros o técnicas que manifiestan la relativa distancia con el acontecer (Verón, 2002). Lo distinto de la situación actual es justamente la interrelación de las distintas esferas, a partir de la articulación llevada a cabo por los medios. 
Un elemento fundamental de este nuevo espacio público lo constituye la exposición lo más amplia posible de la privacidad y la intimidad de estos famosos, en lo que se manifiestan aquellos procesos, propios de esta etapa de la modernización, de transformación profunda de lo público, al impacto de la sicologización y personalización de la vida social (Sennett, 2002; Lipovetsky, 1994), cuestión estrechamente ligada a la atomización y fragmentación social. La privatización de lo social y la socialización de los intereses privados, que había advertido Habermas ya en los años '60 con la clara consecuencia política de la transmutación del ciudadano en consumidor y viceversa, tiene como una de sus expresiones lo ya dicho en términos de la conversión mediática de la privacidad de los famosos en un asunto público y de los problemas sociales y colectivos en dramas humanos singulares y privados.

Una segunda cuestión importante es que esta suerte de nueva forma de mirar la vida social no es ajena a ningún tema o ámbito de la sociedad. De allí la denuncia de algunos sobre la farandulización de la política, por ejemplo, reclamo que se queda en la superficie, si no atiende a que el cambio va mucho más allá que la introducción del formato espectáculo en otras prácticas sociales y que dice relación más bien con una fórmula funcional a las actuales hegemonías orientadas a producir una profunda despolitización de la sociedad.

Con referencia al ámbito de la comunicación, cabe señalar que el fenómeno aludido asume un carácter intermedial, es decir, participan en él de manera articulada e interdependiente, la televisión, la prensa escrita, la Radio y las páginas electrónicas, aunque el eje que dirige esta operación discursiva es fundamentalmente la televisión. De este modo, se manifiesta la tendencia que Verón denomina, en la obra citada, como mediatización general de la sociedad, en que el conjunto de prácticas y relaciones sociales comienzan a estructurarse y a cobrar sentido en tanto realidad social solamente en cuanto estén en relación directa con la acción de los medios. Dicho de otra forma, los distintos ámbitos de la vida social pierden progresivamente su autonomía relativa, en lo que se refiere a su funcionamiento y capacidad de convocatoria. El punto importante de resaltar es que al entrar en la esfera de la mediatización lo deben hacer a partir de los formatos periodísticos y comunicacionales y, en ellos, predomina actualmente el ya mencionado proceso de inversión de lo público y lo privado, base de la creación de la llamada farándula.

En el acápite anterior habíamos señalado que La Cuarta había mostrado durante los ' 90 una particular sensibilidad antes ciertas transformaciones sociales y culturales que se estaban viviendo al calor de la modernización globalizante. El cambio vivido por el diario en el año 2003, aunque un tanto tardío frente a su competidor en el mercado de la prensa, significó también adecuarse a estos nuevos procesos que estaban desarrollándose aceleradamente.

En primer lugar, cabe señalar que no se trató de que el diario haya efectuado un cambio en el tipo de contenidos que trataba, eliminando algunos o incorporando otros nuevos, sino que llevó a cabo una reorganización en términos de la importancia que le confería a unos y otros. El aspecto más visible fue que la crónica roja cedió su lugar de primacía al interior del 
medio a los contenidos de la farándula. El diario de esta manera "...instala un doble cruce entre los medios - la prensa y la televisión- y entre los géneros - el deporte y el espectáculocon un factor temático en común: la exposición de la vida privada de los personajes" (Fuentes y Opazo, 2005: 6).

Dicha reorganización ha afectado especialmente a la Portada. El titular principal dejó de estar dedicado a hechos policiales para ser generalmente consagrado a las vicisitudes de la vida de famosos o a sus intervenciones en algún programa televisivo de la noche anterior (tal como ocurre en Las Ultimas Noticias), lo que no pocas veces genera titulares crípticos o derechamente incomprensibles para quien no sea telespectador asiduo de esos programas. Asimismo, la fotografía de una mujer semidesnuda, anónima pero a la vez reconocible socialmente que revisamos más atrás, ha sido reemplazada por la imagen de algunas de estas figuras femeninas de la farándula, convertidas mediáticamente en una suerte de objeto de deseo masculino masivo.

La crónica policial ha quedado más bien reducida a una sección interna del diario, pero también muchas veces se cruza con la farándula, accediendo por esta razón al titular principal (por ejemplo, con la riña en un bar de un tenista o el regalo de joyas robadas por parte de un futbolista a su esposa, modelo y opinóloga). Lo anterior para reiterar que cualquier ámbito de la vida nacional puede llegar al sitial de noticia central, en tanto esté interrelacionado y formando parte de este nuevo espacio público, construido mediáticamente.

En el marco del actual proceso modernizador, se encuentran al menos debilitados y deslegitimados aquellas discursividades y proyectos políticos y culturales que durante el siglo pasado plantearon una idea de nación y un proyecto de sociedad desde y hacia lo popular, en tanto espacio social con su propia densidad y especificidad histórica no reductible a totalidades mayores. De este modo, la heterogeneización propia del proceso modernizador que se manifiesta en lo económico, laboral, político, cultural, social, etc., bajo la égida de un mercado en permanente expansión que articula las distintas prácticas sociales, reduciéndolas a la esfera del consumo individual, está provocando un profundo proceso de individuación, en el que todo conflicto o problema no puede ser pensado en términos de derecho sino de demandas y todo actor o sujeto social posible es legitimado en tanto consumidor. Sin embargo, esa lógica fragmentaria que solo permite pequeñas y efímeras articulaciones, va acompañada de su contratendencia que, a través del consumo de bienes materiales y simbólicos, provoca simultáneamente procesos crecientes de homogeneización que generan en algunos la ilusión de una suerte de tardía aparición en Chile de la sociedad de masas.

Lo que ocurre es que dificultada materialmente, por decir lo menos, cuando no negada la posibilidad discursiva de un sujeto popular dotado de autonomía, capaz de articular desde si mismo una visión y proyecto de sociedad y de su modernización, cuestión existente en el siglo pasado, el discurso hegemónico recoge ciertos fragmentos y residuos 
de eso anterior y le construye un sentido global al interior del nacionalismo de mercado. Así, lo popular se manifiesta en dos direcciones: en un sentido plebeyo, es decir, como sumatoria de grupos e individuos pobres y necesitados y en tanto que masas consumidoras, en tanto aglomeración que incluso borra las clásicas distinciones entre sectores populares y medios, aproximándose en este último sentido a la noción de multitud que propone Virno para la realidad actual de los sectores subalternos (Virno, 2003)

Es decir, lo popular aparece construido discursivamente a partir de la heterogeneidad y la fragmentación más bien estructural, compensada por la conformación de colectivos plebeyos y multitudinarios de carácter masivo, especialmente articulados por convocatorias mediáticas orientadas hacia distintos ámbitos: el deporte, la recreación, la política e incluso la religión, pero siempre manifestándose efímeramente. Multitudes que se arman y se desarman, sin capacidad de autoconvocatoria, ni de organicidad estable y, menos, de proyectos que se dirijan hacia la totalidad social en una perspectiva estratégica.

El cambio vivido por La Cuarta opera entonces en un contexto en que

...La oferta empresarial y la demanda masiva de espectáculos logran agregar al sujeto popular a una colectividad de masas donde la televisión ocupa el eje de las más diversas interrelaciones socioculturales. En ese ámbito observamos la imbricación cada vez más intensa entre el espacio público y privado... (Fuentes y Otazo, 2005: 168).

De este modo, plantean los autores que la subsistencia de lo popular en La Cuarta, ya no dice relación con los contenidos del diario, ni en la búsqueda de la identificación del lector con la representación de la realidad material de vida de los sectores populares, sino que “...Es a través de las "hablas", de una forma especial de "contar" las historias y del recurso a la imagen que lo popular subyace dentro de la masividad” (Fuentes y Otazo, 2005: 7).

Más aún, la cooptación y el uso de la variedad de recursos lingüísticos y narrativos provenientes del mundo popular le permite contribuir al proceso de construir discursivamente la multitud: “...Así, representa a una masa popular que proyecta tal condición como base de una identidad nacional. Tal como menciona su publicidad, el diario busca hablar en "buen chileno" (Fuentes y Otazo, 2005: 169). Lo anterior permite satisfacer una demanda masiva que busca otro tipo de información frente al modelo tradicional de la noticia en el periodismo liberal moderno, tomando distancia y distinguiéndose del patrón formal, distante y frío del periodismo serio.

En definitiva, el uso de un determinado lenguaje que contiene claves identificatorias que remiten a lo popular, aunque actualmente masificado mucho más allá de aquel, se constituye en un factor central en la integración de los sectores populares fragmentados y heterogéneos a una comunidad nacional construida discursivamente de manera preferente 
desde el mercado. Dichos procesos son los que han permitido la construcción de una suerte de base social de apoyo a las hegemonías actuales, que tendría la fisonomía de una mentalidad de clase media recién llegada a la modernidad y al consumo y con incrustaciones de fragmentos residuales, fuera de contexto histórico y social, de elementos de la cultura popular, desprovistos de toda referencialidad y convertidos en meros significantes.

\section{Referencias bibliográficas}

Alvarado, R. (1997) La prensa sensacionalista: el caso del diario La Cuarta. Documento de Trabajo No. 20, Centro de Investigaciones Sociales, Universidad Arcis, Santiago.

Awad, I.; Soto, G. (2001) "Popularidad de La Cuarta: la clave está en el lenguaje", en Cuadernos de Información No. 14, Escuela de Periodismo, P. Universidad Católica de Chile, Santiago.

Fuentes, C.; Otazo, I. (2005) "Elementos de continuidad y ruptura en La Cuarta: lo popular en el lenguaje". Tesis para optar al grado de Licenciado en Comunicación Social, Escuela Periodismo, U. de Chile, Santiago.

Lipovetsky, G. (1994) La era del vacío. Anagrama, Barcelona.

Martín-Barbero, J. (1987) "La telenovela en Colombia: televisión, melodrama y vida cotidiana", en DIA-LOGOS No. 17, FELAFACS, Lima.

Martín-Barbero, J; Muñoz, S. (1992) Televisión y melodrama, Tercer Mundo, Bogotá.

Monroy, M.; Bahamondes, G. (2001) "La mujer de cabaret: cultura y espectáculos en el diario La Cuarta", Tesis para optar al grado de Licenciado en Comunicación Social, Escuela de Periodismo, Universidad de Chile, Santiago.

Morín, E. (1964) Las estrellas de cine, Eudeba, Buenos Aires.

Ossandón B., C.; Santa Cruz A., E. (2001) Entre las alas y el plomo. La gestación de la prensa moderna en Chile, Arcis-Lom-Dibam, Santiago.

(2005) El estallido de las formas. Chile en los albores de la cultura de masas, Arcis-Lom, Santiago.

Salinas, M. (1996) Risa y cultura en Chile, Documento de Trabajo No. 11, Centro de Investigaciones Sociales, Universidad Arcis, Santiago.

Saitta, S. (1998) Regueros de tinta. Crítica en la década de 1920, Sudamericana, Buenos Aires.

Santa Cruz A., E. (1998) Análisis histórico del periodismo chileno, Nuestra América, Santiago.

-- (2000) "El campo periodístico en Chile a comienzos del siglo XX", en Comunicación y Medios

№ 14, Instituto de Comunicación e Imagen, Universidad de Chile, Santiago.

Sunkel, G. (1986) Razón y pasión en la prensa popular, ILET, Santiago.

------ (2002) La prensa sensacionalista y los sectores populares, Norma, Bogotá.

Verón, E. (2002) El cuerpo de las imágenes, Norma, Bogotá.

Virno, P. (2003) Gramática de la multitud, Traficantes de sueños, Madrid. 